\title{
Serotypes of Campylobacter jejuni isolated from patients attending a diarrhoeal disease hospital in urban Bangladesh
}

\author{
P. K. B. NEOGI and N. S. SHAHID
}

Department of Microbiology, International Center for Diarrhoeal Disease Research, Bangladesh, GPO Box 128 , Dhaka-2, Bangladesh

\begin{abstract}
Summary. The serotypes of strains of Campylobacter jejuni isolated from patients attending the International Center for Diarrhoeal Disease Research, Bangladesh (ICDDR, B), Dhaka, and from animals were ascertained by Penner and Hennessy's (1980) serotyping scheme. Of 102 isolates from man, 74\% were typable and serotypes 53, 15 and 22 predominated. Of 26 isolates from animals, $65 \%$ were typable and serotypes 15 and 53 occurred frequently. The diarrhoeal illnesses associated with different serotypes were similar. In one-third of cases other enteropathogens were present. $C$. jejuni was isolated from $7 \%$ of patients tested in a $4 \%$ sampling system during 1983, and the prevalent serotypes appeared in most months. It is concluded that $C$. jejuni is a common enteropathogen in Bangladesh, that a few serotypes predominate among isolates from both man and animals, and that serotype does not determine clinical symptoms.
\end{abstract}

\section{Introduction}

Soon after Campylobacter jejuni was recognised as an important cause of human gastroenteritis (Skirrow 1977), cases were reported mostly from Western Europe and North America. Reports of poultry and domestic animals as reservoirs (Blaser et al., 1980b) and of possible transmission of the infectious agent via water, milk and food (Robinson et al., 1979; Mentzing, 1981) have emphasised the need to characterise strains of this species. Moreover, the clinical features it produces are not identical everywhere (Blaser et al., 1979; Billingham, 1981) and different serotypes predominate in different countries (Kaijser et al., 1983). Because the organism is biochemically almost inactive and biotyping cannot differentiate between strains of the same species, several serotyping schemes have been developed. Two are well known - one (Penner and Hennessy, 1980) is based upon heat-extracted soluble antigens, and the other (Lior et al., 1982) upon heat-labile antigens. Both schemes have been described as equally efficient for serotyping isolates from different countries (Kaijser et al., 1983; Patton et al., 1983).

In recent years, $C$. jejuni infections in tropical

Received 18 Sep. 1986; accepted 17 Dec. 1986. countries have attracted interest, and reports of infections in man have come from Singapore (Lam, 1981), Thailand (Sabchareon et al., 1982; Supavej et al., 1982), Saudi Arabia (Choudhury et al., 1981) and Nigeria (Low et al., 1981). C. jejuni has been isolated with almost equal frequency from healthy individuals and from patients with diarrhoea in selected groups of the Bangladeshi population (Blaser et al., 1980a). During 1979-1980, the rate of detection in patients attending the International Center for Diarrhoeal Disease Research (ICDDR) was 14\% (Stoll et al., 1982). It has been isolated along with other pathogens from six fatal cases (Butler et al., 1983). It can produce an illness resembling shigellosis among travellers and expatriate residents (Speelman et al., 1983), but such illness is uncommon in indigenous populations (Glass et al., 1983). Serotyping has not been exploited in epidemiological and clinical studies (Blaser et al., 1980a; Glass et al., 1983; Stoll et al., 1982) and, as a result, much about $C$. jejuni infection in Bangladesh remains obscure.

In the present study the method of Penner and Hennessy (1980) has been used to serotype isolates from man and animals in Bangladesh to determine the distribution of serotypes in patients, the value of prevalent serotypes as virulence markers, the seasonality of the disease, and its possible sources or origins. 


\section{Materials and methods}

\section{Isolation and sources of strains}

Based on the registration number at ICDDR, B Treatment Centre, Dhaka, every twenty-fifth patient was included in the study from Jan. 1983 to Dec. 1983 inclusive. On admission, the patient's physical condition, including the state of hydration, was determined by a doctor, and the patient's guardian was interviewed by a trained health assistant to obtain a standard medical history (Stoll et al., 1982). Weight and height were measured for assessment of nutritional status of patients under 10 years old by comparison with the Harvard Standard (Jelliffe, 1966). Stool specimens were screened for known enteropathogens except Norwalk agent and adenovirus.

To isolate and identify Campylobacter spp., fresh stools were cultured on Campy-BAP medium (BBL) in a candle jar at $42^{\circ} \mathrm{C}$ for $48 \mathrm{~h}$ as described by Blaser et al. $(1980 a)$. Characteristic colonies were tested for motility, $\mathrm{H}_{2} \mathrm{~S}$ production, and oxidase and catalase reactions, and stained by Gram's method for morphological examination. Isolates were confirmed as $C$. jejuni by testing their ability to hydrolyse hippurate (Harvey, 1980). The strains were stored at $-70^{\circ} \mathrm{C}$ in Brucella Broth (BBL) containing glycerol $15 \%$. In 1983, 204 isolates (one from each patient) were stored in serial order, and alternate isolates were serotyped. Twenty-six strains isolated from animals during another study in a rural area in 1981-1982 were also examined in this way.

Bacterial pathogens such as Vibrio cholerae O1, V. cholerae non-O1, V. fuvialis, $V$. parahaemolyticus, Aeromonas hydrophila, Plesiomonas shigelloides, Shiguella spp., Salmonella spp. and Yersinia enterocolitica were identified by standard microbiological techniques (Edwards and Ewing, 1972; Lennette et al., 1980). Heat-labile and heatstable toxins of Escherichia coli were sought by the Chinese hamster ovary cell test and the infant mouse assay, respectively (Merson et al., 1979). Rotavirus antigen was identified by enzyme-linked immunosorbent assay (Yolken et al., 1977). Giardia lamblia and Entamoeba histolytica were identified by direct microscopy of unconcentrated faeces during routine examination.

\section{Serotyping}

The serotype of each strain was determined by detecting the saline-extracted thermostable antigens by the passive haemagglutination technique as described by Penner and Hennessy (1980) and Penner et al. (1983). Reference strains were obtained from Dr J. L. Penner, Department of Medical Microbiology, Faculty of Medicine, University of Toronto, Canada. Antisera to reference strains were prepared in rabbits by the method of Penner et al. (1980) except that Campy-BAP medium was used instead of blood agar to propagate the strains. Most of the sera had agglutinating titres of 2560-5120. These were used in the tests at an initial dilution of 1 in 100. Each isolate was tested against the panel of antisera and assigned a serotype according to the antiserum in which agglutination occurred. When an isolate was agglutinated by more than one antiserum, the highest agglutinating titre was accepted as indicating the particular serotype.

\section{Results}

\section{Serotypes of isolates from man}

Of 102 strains, 75 were typable, four reacted equally with three different antisera, and 23 did not agglutinate with any antiserum. Although with many strains cross-agglutination occurred with two or three different antisera, the titre in crossreactions was generally three- or four-fold lower than the highest titre obtained, on which basis the serotype was determined. Nineteen different serotypes were identified among the isolates from patients with a panel of antisera that could identify 42 specific antigens; the distribution of serotypes is shown in table I. Serotypes 53, 15 and 22 were dominant, constituting, respectively, $23.5 \%, 15.7 \%$ and $6.9 \%$ of the strains.

\section{Clinical features}

Three serotypes occurred most often among isolates from 31 patients in whom $C$. jejuni was the sole enteropathogen. The age and sex distribution in these patients and the clinical features associated with each serotype are shown in tables II and III respectively. The number of infections was highest in the age-groups under 1 year and 1-5 years; the sex ratio was $3: 2(\mathrm{M}: \mathrm{F})$ and four patients only were malnourished. Among the clinical symptoms, a mild to moderate diarrhoea (mostly of watery stool), vomiting, mild dehydration and absence of fever were noteworthy. The duration of diarrhoea before coming to hospital was generally $2-4$ days.

Table I. Distribution of serotypes among 102 clinical isolates

\begin{tabular}{lc} 
Serotype & Percentage of isolates \\
\hline 53 & $23 \cdot 5$ \\
15 & $15 \cdot 7$ \\
22 & $6 \cdot 9$ \\
41 & $4 \cdot 0$ \\
10,33 & $3 \cdot 0$ (each) \\
$5,13,21,23,38$ & $2 \cdot 0$ (each) \\
$1,9,16,18,19,35,36,43$ & $1 \cdot 0$ (each) \\
Untypable & $22 \cdot 5$ \\
Multireactive & $4 \cdot 0$ \\
& \\
\hline
\end{tabular}


Table II. Predominant serotypes related to age and sex of patients infected only with $C$. jejuni

\begin{tabular}{|c|c|c|c|c|c|c|c|c|}
\hline \multirow[b]{3}{*}{ Serotype } & \multirow[t]{3}{*}{ Total } & \multicolumn{7}{|c|}{ Number of isolates in } \\
\hline & & \multicolumn{5}{|c|}{ age group (years) } & \multicolumn{2}{|r|}{ sex } \\
\hline & & $<1$ & $1-5$ & $6-12$ & $13-25$ & $>25$ & male & female \\
\hline 53 & 13 & 4 & 6 & 1 & 1 & 1 & 8 & 5 \\
\hline 15 & 13 & 8 & 4 & 0 & 1 & 0 & 6 & 7 \\
\hline 22 & 5 & 2 & 2 & 1 & $\mathbf{0}$ & 0 & 4 & 1 \\
\hline
\end{tabular}

The three prevalent serotypes were isolated also from another 16 patients who had mixed infections with enteric pathogens such as enterotoxigenic $E$. coli (6 cases), $V$. cholerae $\mathrm{O} 1$ ( 5 cases), rotavirus ( 3 cases) and $S$. flexneri ( 2 cases). Infections in which $C$. jejuni was present with other pathogens were not restricted to specific age groups; five of the patients were malnourished. Among the patients with polymicrobial infections, five were moderately dehydrated and six were severely dehydrated from frequent purging of liquid stool.

\section{Seasonality}

From January to December inclusive, 2860 systematically selected patients were studied: $C$. jejuni was isolated from 204 of them. The figure

Table III. Clinical features in patients with $C$. jejuni as sole pathogen

\begin{tabular}{|c|c|c|c|}
\hline \multirow[b]{2}{*}{ Clinical feature } & \multicolumn{3}{|c|}{$\begin{array}{l}\text { Percentage of patients with the } \\
\text { given feature in infections with } \\
\text { serotype }\end{array}$} \\
\hline & $53(n=1$ & $(n=13)$ & $22(n=5)$ \\
\hline $\begin{array}{l}\text { Frequency of stool } \\
\text { Low (3-5/day) } \\
\text { Moderate (6-10/day) } \\
\text { High (>10/day) }\end{array}$ & $\begin{array}{l}23 \\
46 \\
31\end{array}$ & $\begin{array}{l}46 \\
38 \\
15\end{array}$ & $\begin{array}{l}20 \\
60 \\
20\end{array}$ \\
\hline $\begin{array}{l}\text { Symptoms } \\
\text { Watery stool } \\
\text { Bloody stool } \\
\text { Vomiting } \\
\text { Mild fever }(37 \cdot 0- \\
\left.-37 \cdot 7^{\circ} \mathrm{C}\right) \\
\text { Distended abdomen }\end{array}$ & $\begin{array}{l}85 \\
15 \\
46\end{array}$ & $\begin{array}{r}92 \\
8 \\
54 \\
\\
23 \\
15\end{array}$ & $\begin{array}{l}80 \\
20 \\
40\end{array}$ \\
\hline $\begin{array}{l}\text { Dehydration } \\
\text { Mild } \\
\text { Moderate } \\
\text { Severe }\end{array}$ & $\begin{array}{r}62 \\
23 \\
0\end{array}$ & $\begin{array}{r}54 \\
13 \\
8\end{array}$ & $\begin{array}{r}40 \\
40 \\
0\end{array}$ \\
\hline
\end{tabular}

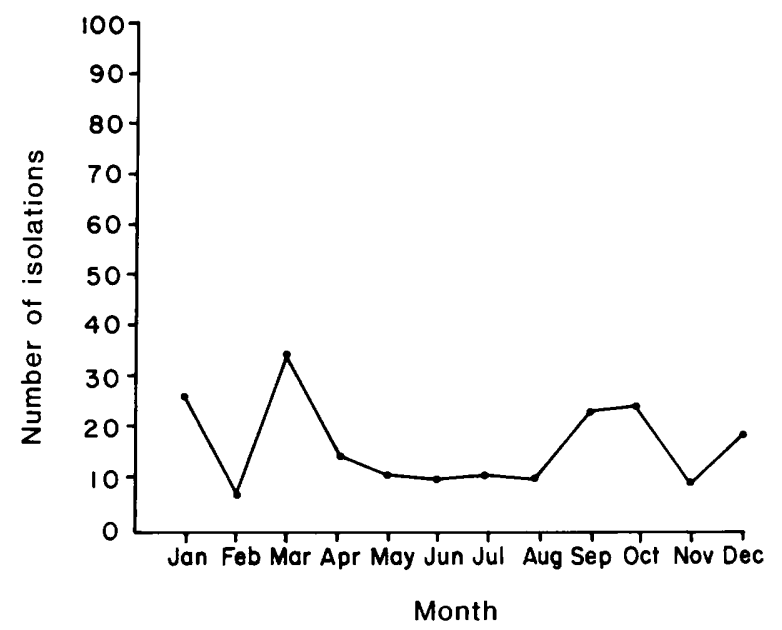

Figure. The seasonal incidence of $C$. jejuni isolations in 1983.

shows that slightly more strains were isolated during the cold months of the year. Mixed infections with other enteric pathogens were found in $35 \%$ of cases in all months except April. Serotypes 15 and 22 were isolated in the months from March to September, whereas serotype 53 appeared in most months of the year.

\section{Serotypes of isolates from animals}

Twenty-six strains from 300 poultry and domestic animals were serotyped. Of the isolates from animals, 17 were typable, and serotypes 15 and 53 were most common (table IV). Serotypes 5, 15, 16, 25,35 and 53 were found in household poultry or animals; all of them except serotype 25 were common in human patients.

\section{Discussion}

Although it was expected that nearly $95 \%$ of isolates would be typable by Penner's serotyping method, only $74 \%$ were typable. Three serotypes predominated among isolates from man. Crossreactions, which were often encountered, may be due to the complexity and heterogeneity of $C$. jejuni antigens. It is likely that different serotypes predominate in different geographical localities.

In Bangladesh, the symptoms shown by patients from whom $C$. jejuni was isolated were mild to moderate purging of watery stool and mild dehydration, but fever was absent. Children under 5 years of age, of both sexes, were most often infected. The majority of Bangladeshi children suffering from $C$. jejuni enteritis were not malnourished. There were no significant differences between the clinical 
Table IV. Distribution of serotypes in 26 poultry and pets

\begin{tabular}{|c|c|c|c|c|c|c|c|c|}
\hline \multirow[b]{2}{*}{ Origin } & \multicolumn{8}{|c|}{ Number of strains of serotype } \\
\hline & Total & 5 & 15 & 16 & 25 & 35 & 53 & Untypable \\
\hline Chicken & 16 & 1 & 3 & 0 & 1 & 0 & 3 & 8 \\
\hline Duck & 2 & $\mathbf{0}$ & 1 & 1 & $\mathbf{0}$ & 0 & 0 & 0 \\
\hline Cat & 1 & $\mathbf{0}$ & 1 & 0 & 0 & 0 & 0 & 0 \\
\hline Goat & 3 & 0 & 0 & 0 & 0 & 2 & 0 & 1 \\
\hline Sheep & 1 & 0 & 0 & 0 & $\mathbf{0}$ & 0 & 1 & 0 \\
\hline Cow & 3 & 0 & 2 & 1 & $\mathbf{0}$ & 0 & 0 & 0 \\
\hline Total & 26 & 1 & 7 & 2 & 1 & 2 & 4 & 9 \\
\hline
\end{tabular}

features of illnesses associated with different serotypes of $C$. jejuni (tables II and III). It may be assumed, therefore, that $C$. jejuni produces mild diarrhoea, and that all clinical isolates cause similar disease irrespective of their serotypes. By contrast, patients who had polymicrobial infections including $C$. jejuni had moderate or severe diarrhoea. The severity of illness in multiple infection may be due to dominance of the other potential pathogen or to synergy. Dominance has been reported in some fatal cases (Butler et al., 1983).

The $4 \%$ sampling system used in this study was found to be suitable for determining the seasonal pattern of various enteropathogens in a particular area (Stoll et al., 1982). In the present study, although the incidence of $C$. jejuni infection was slightly higher in cold months, it did not show any clear seasonal trend; the monthly rate of isolation was in the range $4-15 \%$ with an average of $7 \%$. Though serotype 53 was found throughout the year, serotypes 15 and 22 appeared only in hot months. In an earlier survey in rural Bangladesh, $C$. jejuni strains were isolated every month in almost equal

\section{REFERENCES}

Billingham J D 1981 Campylobacter enteritis in the Gambia. Transactions of the Royal Society of Tropical Medicine and Hygiene 75: 641-644.

Blaser M J, Berkowitz I D, Laforce F M, Cravens J, Reller L B, Wang W L L 1979 Campylobacter enteritis: clinical and epidemiological features. Annals of Internal Medicine 91 : 179-185.

Blaser M J, Glass R I, Huq M I, Stoll B, Kibriya G M, Alim A R M A 1980a Isolation of Campylobacter fetus subsp. jejuni from Bangladeshi children. Journal of Clinical Microbiology 12:744-747.

Blaser M J, Laforce F M, Wilson N A, Wang W L L $1980 b$ Reservoirs for human campylobacteriosis. Journal of Infectious Diseases 141 : 665-669.

Butler T, Islam M, Islam R, Speelman P, Azad A 1983 Postmortem findings in six cases of fatal Campylobacter infection in Bangladesh. In: Pearson A D et al. (eds), frequency (Glass et al., 1983), but so far there has been no report of a campylobacter epidemic in Bangladesh.

Rearing of animals such as chickens, ducks, cats, dogs, sheep, goats and cows is common in rural Bangladesh. Serotypes 15 and 53, predominant in man, were common also in animals. Altogether six serotypes, five of which were common in urban patients, were found in rural poultry and pets (table IV). This may point to the possible origin of strains infecting man.

The somatic antigens of $C$. jejuni are heterogeneous. This limited study demonstrates that serotyping based on $\mathrm{O}$-antigen determination is an excellent marker for $C$. jejuni strains but that serotype does not determine clinical symptoms.

We are grateful to Dr J. L. Penner for providing reference strains and to DrD. A. Sack for guidance. We thank Mohammad Shahjahan Miah and Mr Priyatosh Sukul for their technical assistance. The study was supported by the Disease Transmission Programme, International Center for Diarrhoeal Disease Research, Bangladesh.
Campylobacter II. Public Health Laboratory Service, London, p. 19.

Chowdhury M N H, Mahgoub, El-Sheikh 1981 Gastroenteritis due to Campylobacter jejuni in Riyadh, Saudi Arabia. Transactions of the Royal Society of Tropical Medicine and Hygiene 75:759-361.

Edwards P R, Ewing W H (eds) 1972 Identification of Enterobacteriaceae, 3rd edn. Burgess Publishing Company, Minneapolis, Minnesota, pp. 7-20.

Glass R I, Stoll B J, Huq M I, Struelens M J, Blaser M, Kibriya A K M G 1983 Epidemiologic and clinical features of endemic Campylobacter jejuni infection in Bangladesh. Journal of Infectious Diseases 148:292-296.

Harvey S M 1980 Hippurate hydrolysis by Campylobacter fetus. Journal of Clinical Microbiology 11 :435-437.

Jelliffe D B (ed) 1966. The assessment of the nutritional status of the community. World Health Organization, Monograph Series no. 53, Geneva, pp. 221-242.

Kaijser B, Sjogren E 1983 The significance of serotyping 
Campylobacter jejuni. In: Pearson A D et al. (eds), Campylobacter II. Public Health Laboratory Service, London, p. 95.

Lam S 1981 Campylobacter enteritis in Singapore. Singapore Medical Journal 22:173-175.

Lennette E H, Barlows A, Hausier W J, Truant J P (eds) 1980 Manual of clinical microbiology, 3rd edn. American Society for Microbiology, Washington, D.C., pp 195-234.

Lior H, Woodward D L, Edgar J A, Laroche L J, Gill P 1982 Serotyping of Campylobacter jejuni by slide agglutination based on heat-labile antigenic factors. Journal of Clinical Microbiology 15 : 761-768.

Low D C, Lawande R V, Hall C 1981 Campylobacter enteritis in Northern Nigeria. Transactions of the Royal Society of Tropical Medicine and Hygiene 75: 757.

Mentzing L 1981 Waterborne outbreaks of Campylobacter enteritis in Central Sweden. Lancet 2:352-354.

Merson M H, Sack R B, Kibriya A K M G, Al-Mahmood A, Adamed Q S, Huq I 1979 The use of colony pools for diagnosis of enterotoxigenic Escherichia coli diarrhoea. Journal of Clinical Microbiology 9:493-497.

Patton C M, Barrett T J, Morris G K 1983 Serotyping Campylobacter jejuni by two systems: the CDC experience. In: Pearson A D et al. (eds), Campylobacter II. Public Health Laboratory Service, London, p. 96.

Penner J L, Hennessy J N 1980 Passive hemagglutination technique for serotyping Campylobacter fetus subsp. jejuni on the basis of soluble heat-stable antigens. Journal of Clinical Microbiology 12: 732-737.
Penner J L, Hennessy J N, Congi R V 1983 Serotyping of Campylobacter jejuni and Campylobacter coli on the basis of thermostable antigens. European Journal of Clinical Microbiology 2: 378-383.

Robinson D A, Edgar W J, Gibson G L, Matchett A A, Robertson L 1979 Campylobacter enteritis associated with consumption of unpasteurised milk. British Medical Journal 1: 1171-1173.

Sabchareon A, Supavej S, Attanath P, Tapchaisri P 1982 Campylobacter jejuni in an orphanage in Bangkok. Southeast Asian Journal of Tropical Medicine and Public Health 13: 490.

Skirrow M B 1977 Campylobacter enteritis: a "new" disease. British Medical Journal 2:9-11.

Speelman P, Struelens M J, Sanyal S C, Glass R I 1983 Campylobacter jejuni enterocolitis in travellers' diarrhoea in Bangladesh. In: Pearson A D et al. (eds), Campylobacter II. Public Health Laboratory Service, London, p. 14.

Stoll B J, Glass R I, Huq M I, Khan M U, Holt J E, Banu H 1982 Surveillance of patients attending a diarrhoeal disease hospital in Bangladesh. British Medical Journal 285: 11851188.

Supavej S, Lexomboon U, Simasathien S 1982 Occurrence of Campylobacter enteritis in Thai children. Southeast Asian Journal of Tropical Medicine and Public Health 13:489.

Yolken R H et al. 1977 Enzyme-linked immunosorbent assay (ELISA) for detection of human reovirus-like agent of infantile gastroenteritis. Lancet 2:263-267. 